(2) OPEN ACCESS

\title{
Exploring psychosocial stressors as contributors to racial disparity in end-stage renal disease
}

\author{
Peter Van Buren (10) 1,2
}

${ }^{1}$ Internal Medicine, Division of Nephrology, UT Southwestern Medical School, Dallas, Texas, USA ${ }^{2}$ Dallas Veterans Affairs Medical Center, Dallas, Texas, USA

Correspondence to Dr Peter Van Buren, Internal Medicine, Division of Nephrology, UT Southwestern Medical School, Dallas, TX 75390, USA;

peter.vanburen@ utsouthwestern.edu

Accepted 13 January 2021

\section{SLinked}

http://dx.doi.org/10. 1136/jim-2020-001510

\section{Check for updates}

(C) American Federation for Medical Research 2021. Re-use permitted under CC BY-NC. No commercial re-use. Published by BMJ.

To cite: Van Buren $\mathrm{P}$. $J$ Investig Med 2021;69:307-308.
Chronic kidney disease (CKD) is present in 15\% of the US population. ${ }^{1}$ Despite our knowledge of some of the risk factors that contribute to progression to end-stage renal disease (ESRD) such as hypertension and proteinuria, the unadjusted incidence of ESRD continues to increase. One persistent and troubling finding is the large racial disparity that exists in the ESRD population, and currently the adjusted prevalence of African Americans with ESRD is more than three times higher than that of whites. ${ }^{1}$ There is a need for identification of additional risk factors that put African Americans at high risk ESRD so that providers can implement appropriate interventions at an earlier stage.

When defined as an estimated glomerular filtration rate (eGFR) of $<60 \mathrm{~mL} / \mathrm{min}$ or $>30 \mathrm{mg} / \mathrm{g}$ albumin/creatinine ratio on a spot urine sample, CKD is present in $16 \%$ of African Americans and $15.7 \%$ of whites. ${ }^{1}$ The racial disparity that exists in the ESRD population is likely multifactorial, but more rapid progression of CKD to ESRD among African Americans is a particular concern. Analysis from the AfricanAmerican Study of Kidney Disease and Hypertension (AASK) Trial showed that participants in this study were more likely to progress to ESRD than to experience major cardiovascular events or mortality with higher baseline proteinuria being a risk factor for ESRD. ${ }^{2}$ The AASK Trial provides insight into ESRD risk in a specific group of patients: African Americans with CKD presumably due to hypertensive nephrosclerosis (diabetes and proteinuria $>2.5 \mathrm{~g} /$ day were exclusion criteria). Since that study, others have shown that African Americans experience faster decline in kidney function even prior to the development of CKD. While controlling for traditional risk factors, Peralta et al showed the trajectory of eGFR decline in individuals with preserved baseline eGFR was steeper in African Americans than in other races. ${ }^{3}$ Consequently, that same study found the incidence of CKD (defined by eGFR $<60 \mathrm{~mL} / \mathrm{min}$ ) was also higher in African Americans. Another study specifically looking at younger individuals (age 18-30 years) with limited baseline cardiovascular disease found that eGFR declined more rapidly and at an earlier age in African-American participants compared with white participants. ${ }^{4}$

The manuscript 'The Association between Goal-Striving Stress and Rapid Kidney Function
Decline among African Americans: The Jackson Heart Study ${ }^{5}$ published in this issue of Journal of Investigative Medicine aims to address the fact that traditional risk factors do not fully explain the disproportionate risk of ESRD in African Americans. In this study, the authors explore the association between rapid kidney function decline (RKFD) with a non-traditional risk factor, goal-striving stress (GSS), in African Americans with preserved eGFR and no proteinuria at baseline. The metric of GSS is a psychosocial stressor determined by a calculation of an individual's aspiration and achievement, weighted by the disappointment in the difference between the two. The RKFD metric was defined as a decrease in eGFR $>4 \mathrm{~mL} / \mathrm{min} /$ year from baseline to follow-up. The authors have previously found there to be a significant association between GSS and prevalent CKD in African Americans, ${ }^{6}$ which generates the hypothesis that GSS could contribute to or predict the development of kidney disease. The authors propose several potential mechanisms by which GSS negatively influences health, including abnormal physiologic regulation of the autonomic nervous system as well as changes in the immune, metabolic, and cardiovascular systems. The current work expands on the prevalence data by finding that among those individuals with normal renal function at baseline, the baseline GSS was associated with RKFD over the observation period. A prior analysis of this same cohort identified that age, diabetes, higher systolic blood pressure, and low/middle income status were associated with a higher risk of a 30\% decrease in eGFR during follow-up. ${ }^{7}$ In the current study, the participants with higher GSS overall appeared to be healthier due to younger age, higher baseline eGFR, and less hypertension, diabetes or cardiovascular disease history. In the initial unadjusted analysis, there was no difference in RKFD between the groups of GSS. When controlling for all of the abovementioned baseline variables, there was a significant association between GSS and RKFD when GSS was analyzed as both a continuous variable and a categorical variable. In more advanced models accounting for discrimination and baseline cortisol, high GSS was still associated with RKFD although the continuous association was 
no longer significant. The CKD incidence or its association with GSS were not reported in the paper.

The important implications of this research are apparent when looking at the baseline characteristics of participants with high GSS. Other than more frequent use of tobacco/ alcohol, these individuals appeared to be in better health and have fewer risk factors for declining eGFR than those with lower GSS. However, the high GSS group experienced similar rates of RKFD as other participants with more traditional risk factors. Furthermore, when accounting for baseline differences, GSS was independently associated with RKFD. These findings suggest that consideration of this psychosocial stressor might reclassify some individuals originally considered at low risk for RKFD into a higherrisk category. Recognition of this otherwise overlooked risk could potentially allow for closer monitoring and earlier implementation of evidence-based strategies to slow kidney function loss in such individuals. The findings in this manuscript should pave the way for additional research to address questions that could not be fully answered from the available data. Although hypertension was included in the analysis as a categorical variable, the actual blood pressure measurements were not reported or incorporated into the analyses. It will be important to better understand the nature of the relationship between GSS and blood pressure as some research has shown GSS to be associated with higher blood pressure. ${ }^{8}$ Furthermore, cortisol did not have a large impact on the association between GSS and RDKF. The authors point out there are numerous other mechanisms that may be involved in how GSS is associated with RKFD such as sympathetic nervous system activity, and further research will be necessary to uncover other potential mediators of the GSS/RKFD relationship. The fact that DNA was obtained as part of the baseline assessment provides opportunity to better understand why GSS might have been associated with RKFD in some but not all of the participants. Finally, it must ultimately be determined if modification of GSS itself translates into less risk for RKFD and incident $\mathrm{CKD} / \mathrm{ESRD}$.

In conclusion, the authors present a well-conducted analysis to demonstrate that baseline GSS is an independent risk factor for large decreases in eGFR over time among African Americans with normal baseline renal function. The mechanisms behind this association and causality are not yet demonstrated, but the identification of novel metrics such as this is an important step. Racial disparity exists in ESRD, and African Americans experience more rapid decline in renal function than others. As we continue to learn more about the biologic background and consequences of GSS and other psychosocial stressors, we might be able to recognize high-risk individuals at an earlier stage and reduce the time for them receiving appropriate interventions.

Contributors PVB contributed to all aspects of this editorial.

Funding The authors have not declared a specific grant for this research from any funding agency in the public, commercial or not-for-profit sectors.

Competing interests None declared.

Patient consent for publication Not required.

Provenance and peer review Commissioned; internally peer reviewed.

Author note The opinions in this editorial are reflective of the author, Dr. Van Buren, and are not necessarily reflective of any opinion or policy of the Department of Veterans Affairs or of University of Texas Southwestern Medical Center.

Open access This is an open access article distributed in accordance with the Creative Commons Attribution Non Commercial (CC BY-NC 4.0) license, which permits others to distribute, remix, adapt, build upon this work noncommercially, and license their derivative works on different terms, provided the original work is properly cited, an indication of whether changes were made, and the use is non-commercial. See: http://creativecommons.org/ licenses/by-nc/4.0/.

\section{ORCID iD}

Peter Van Buren http://orcid.org/0000-0002-4392-1163

\section{REFERENCES}

1 System USRD. 2019 USRDS annual data report: epidemiology of kidney disease in the United States. National Institute of health, National Institute of diabetes and digestive and kidney disease. Bethesda, MD, 2019.

2 Alves TP, Wang X, Wright JT, et al. Rate of ESRD exceeds mortality among African Americans with hypertensive nephrosclerosis. J Am Soc Nephrol 2010;21:1361-9.

3 Peralta CA, Katz R, DeBoer I, et al. Racial and ethnic differences in kidney function decline among persons without chronic kidney disease. J Am Soc Nephrol 2011;22:1327-34.

4 Peralta CA, Vittinghoff E, Bansal N, et al. Trajectories of kidney function decline in young black and white adults with preserved GFR: results from the coronary artery risk development in young adults (cardia) study. Am I Kidney Dis 2013;62:261-6.

5 Cain-Shields L, Glover L, Young B. Association between goal-striving stress and rapid kidney function decline among African Americans: the Jackson heart study. J Investig Med 2021;69:382-7.

6 Cain LR, Glover L, Young B, Cain LG L, Sims M, et al. Goal-striving stress is associated with chronic kidney disease among participants in the Jackson heart study. J Racial Ethn Health Disparities 2019;6:64-9.

7 Young BA, Katz R, Boulware LE, et al. Risk factors for rapid kidney function decline among African Americans: the Jackson heart study (JHS). Am J Kidney Dis 2016;68:229-39.

8 Sellers SL, Neighbors HW, Zhang R, et al. The impact of goal-striving stress on physical health of white Americans, African Americans, and Caribbean blacks. Ethn Dis 2012;22:21-8. 